\title{
Structural and Morphological Characterization of Magnetron Sputtered Nanocrystalline Vanadium Oxide Films for Thermochromic Smart Surfaces
}

\author{
C. Batista ${ }^{a}$, V. Teixeira ${ }^{b}$ and J. Carneiro \\ University of Minho, GRF - Functional Coatings Group, Department of Physics, Campus de \\ Azurém, 4800-058 Guimarães, Portugal \\ acbatista@fisica.uminho.pt, bvasco@fisica.uminho.pt
}

received paper 23.09.2007, received revised paper 20.12.2007, accepted date, 20.01.2008

Keywords: Vanadium oxide; Nanocrystalline films; Magnetron sputtering; Thermochromism

\begin{abstract}
Nanocrystalline vanadium oxide thin films have been deposited by reactive DC magnetron sputtering onto glass substrates under different processing conditions. Structural analysis and phase identification have been carried out by means of X-ray diffractometry (XRD). The surface morphologies of the different films have been examined by both scanning electron microscopy (SEM) and atomic force microscopy (AFM). The XRD results revealed single and multiple phase oxides such as $\mathrm{VO}_{2}(\mathrm{~B}), \mathrm{VO}_{2}(\mathrm{M}), \mathrm{V}_{2} \mathrm{O}_{5}$, etc. with considerable differences concerning to surface morphologies, as observed by SEM and AFM. The effects the $\mathrm{O}_{2} / \mathrm{Ar}$ flow ratio, DC current, and working pressure on the phases formed and growth rates is discussed. Moreover, $\mathrm{VO}_{2}(\mathrm{M})$ films exhibited different morphologies concerning to grain size and shape as well as dissimilar preference in crystal orientation, as a result of the processing conditions. The optical/thermochromic response of the $\mathrm{VO}_{2}(\mathrm{M})$ specimens deposited under different growth rate conditions was evaluated by optical spectrophotometry and related to the respective structural characteristics.
\end{abstract}

\section{Introduction}

Vanadium oxides are a class transition-metal compounds which undergo an abrupt reversible transition from a non-metallic to a metallic state with increasing temperature. This first-order transition is accompanied by a large change of electrical resistivity and reflectance in the infrared region [1] which makes these materials attractive for applications such as optical/electrical switching devices [2-4], electrochromic systems [5], data storage devices [6, 7], etc. Among them, $\mathrm{VO}_{2}$ is the most interesting because its transition temperature is close to room temperature, $\sim 68^{\circ} \mathrm{C}$ [1], and therefore is being under many studies in an effort to apply it in smart energy efficient windows with active solar control [8-12]. The stoichiometry of $\mathrm{VO}_{2}$ has been reported as a determinant factor for an improved thermochromic performance [13-15]. However, stoichiometric $\mathrm{VO}_{2}$ is difficult to deposit because of a narrow stability range resulting from the complex vanadium-oxygen reactive system [16-18]. Moreover, The magnitude of the change and the respective hysteresis depend on the properties of the film, i.e. crystallinity, grain size, impurities and adherence, as a consequence of the processing conditions [14, 15, 19].

Reactive DC magnetron sputtering, which is one of the most promising techniques for largearea and large-scale coating applications [20,21], has been used to deposit vanadium oxide films. A major problem during the preparation of vanadium oxides in thin film form is the very narrow range of processing conditions in which a stable single phase occur [18].

In this paper we present a study with focus on the formation of vanadium oxide films by reactive DC magnetron sputtering. The role of the processing parameters on the phases formed, crystal orientation and film morphology is discussed. Moreover, the optical/thermochromic response of $\mathrm{VO}_{2}(\mathrm{M})$ films prepared under different conditions is evaluated and correlated to crystal orientation and morphology. 


\section{Experimental}

DC magnetron sputtering was utilized to deposit the vanadium oxide films onto $1 \mathrm{~mm}$ thick glass slides. The process was carried out by sputtering a $99.95 \%$ purity round vanadium target in a controlled argon-oxygen atmosphere. Prior to the deposition the vacuum chamber was evacuated down to a pressure of about $3 \times 10^{-5}$ mbar. A pre-sputtering of 10 minutes with argon was carried out before each deposition to remove the oxides eventually formed at the surface of the target. For the deposition of the vanadium oxide films, the sputtering and reactive gases were introduced into the chamber separately through two gas mass flow controllers. There have been prepared two series of films with distinctive growth rate conditions. In the first, the $\mathrm{O}_{2} / \mathrm{Ar}$ flow has been varied from 1.05 to $3.55 \%$ and from 6.25 to $50 \%$, maintaining a constant power. Also, the DC current has been varied from 0.28 to $0.32 \mathrm{~A}$ at a constant $\mathrm{O}_{2} / \mathrm{Ar}$ flow ratio of $2.61 \%$. The second series has been prepared under a $\mathrm{O}_{2} / \mathrm{Ar}$ flow ratio of $14.6 \%$ and a DC current of $0.5 \mathrm{~A}$, at a lower total pressure. One film has been doped with tungsten during deposition of vanadium oxide by sputtering from tungsten-doped vanadium target. After the depositions, all films cooled down to room temperature in vacuum inside the chamber.

The structural analysis and determination of the phases formed under the different processing conditions has been done by using a X-ray diffractometer operating with a continuous scan of $\mathrm{Cu}$ $\mathrm{K}_{\alpha 1}$ radiation with $\lambda=1.54056 \AA$. Once the vanadium oxide phase(s) of each sample has been identified some of the samples were chosen for further analyses. Scanning electron microscopy (SEM) has been used with the purpose of examining the surface morphology of the different phases formed. Moreover, AFM analyses have also been performed as a complement to SEM in order to quantify roughness parameters and to determine average grain sizes. An area of $1 \mathrm{x} 1 \mu \mathrm{m}^{2}$ has been chosen for the scan.

The samples containing single phase $\mathrm{VO}_{2}(\mathrm{M})$ were subjected to optical spectrophotometry analysis so the optical behavior could be evaluated. It has been done by measuring the near-normal transmittance from 250 to $2500 \mathrm{~nm}$ under and above the switching temperature. The determination of the switching temperature was carried out by evaluating the transmittance change with temperature.

\section{Results and discussion}

Structural analysis and phase identification. Fig. 1 shows the vanadium oxide phases formed with different $\mathrm{O}_{2} / \mathrm{Ar}$ flow ratios used in the experiment. It can be seen that all spectra show a broad background hump centered around $2 \theta=27^{\circ}$ which is due to the amorphous glass substrate, as confirmed by comparing with the spectra of an uncoated substrate. Concerning to the films themselves, when the $\mathrm{O}_{2} /$ Ar ratio is increased phases richer in oxygen are preferred to be formed. The lower pattern of sample deposited with $6.25 \%$ presents $\mathrm{V}_{4} \mathrm{O}_{7}, \beta-\mathrm{V}_{2} \mathrm{O}_{5}$ and a small amount of $\mathrm{VO}_{2}(\mathrm{~B})$. Intermediate patterns show mixtures of various oxides and the top pattern, which has been obtained for the higher $\mathrm{O}_{2} /$ Ar ratio, reveals exclusively single phase $\mathrm{V}_{2} \mathrm{O}_{5}$.

As in Fig. 1, Fig. 2 shows the vanadium oxide phases formed depending on the oxygen flow ratio used in the experiment. However, in this case much lower $\mathrm{O}_{2} / \mathrm{Ar}$ flow ratios were used as well as constant and higher pressure. It can be seen that with an increase of the oxygen flow there will be also a tendency to form vanadium oxides with higher oxygen valence. For the chosen conditions, a $\mathrm{O}_{2} / \mathrm{Ar}$ flow ratio of $1.51 \%$ was found to be appropriate to form the thermochromic $\mathrm{VO}_{2}(\mathrm{M})$ phase (Fig. 2b). The main crystal orientation for this phase was found to be in the (011) direction. 


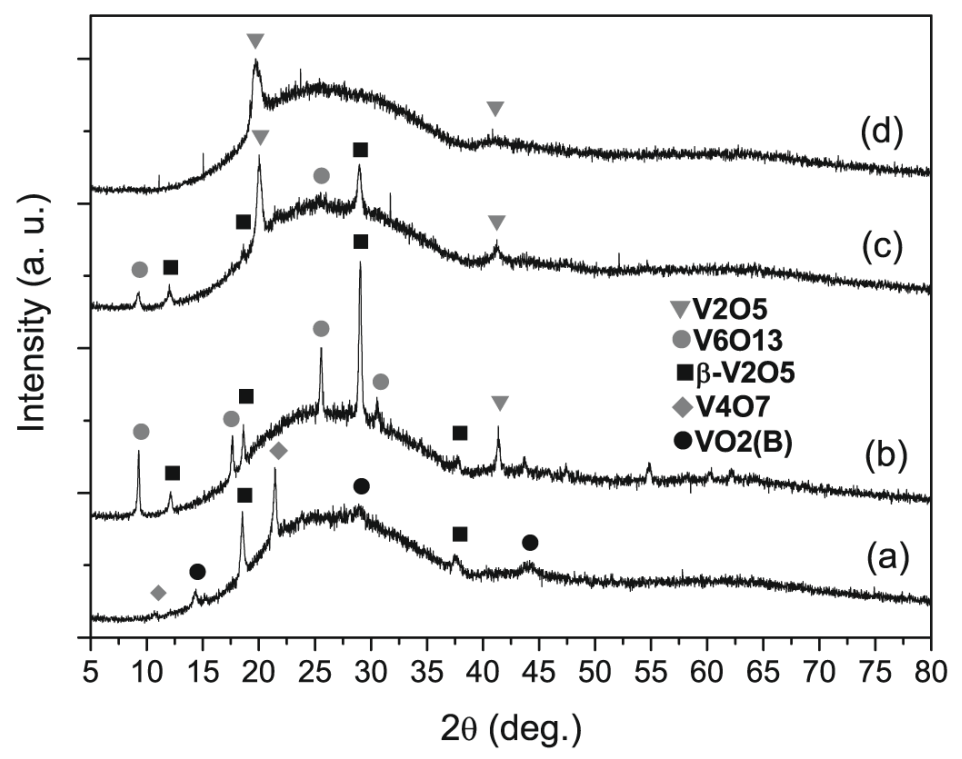

Fig. 1. XRD spectra showing the dependence of the vanadium oxide phases formed on the $\mathrm{O}_{2} / \mathrm{Ar}$ flow ratio: (a) $6.25 \%$, (b) $12.5 \%$, (c) $25 \%$, (d) $50 \%$. Deposition parameters: $\mathrm{I}(\mathrm{A})=0.2$; Time(min.) $=20 ;$ Temperature $\left({ }^{\circ} \mathrm{C}\right)=400 ;$ Work pressure $($ mbar $)=3.9 \times 10^{-3}$ to $6.4 \times 10^{-3}$.

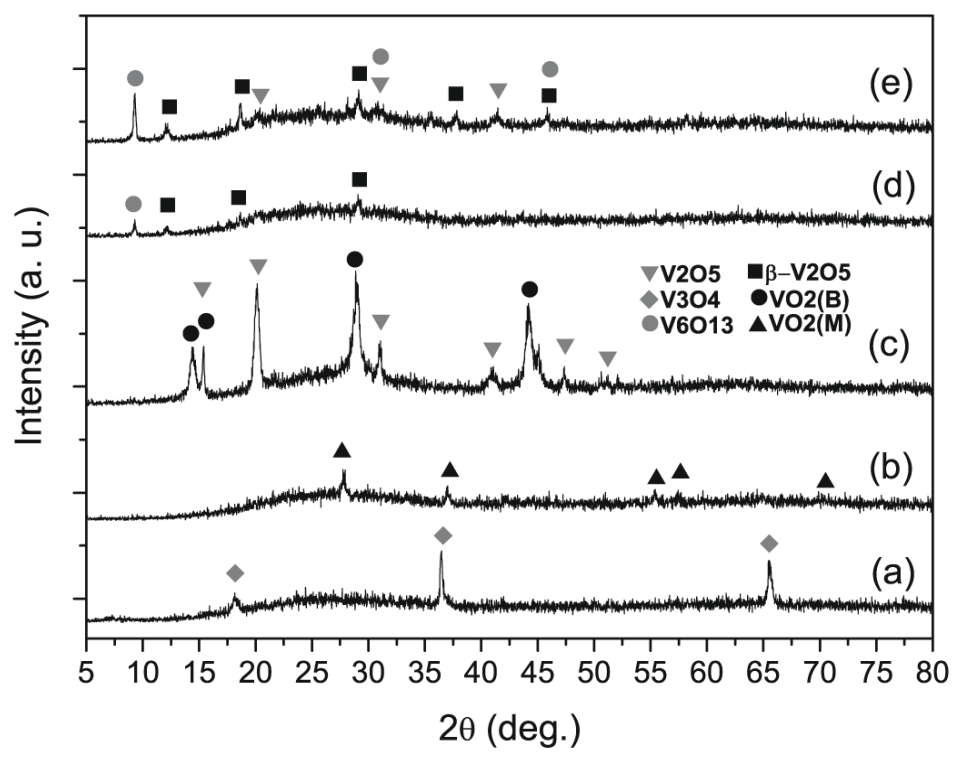

Fig. 2. XRD spectra showing the dependence of the vanadium oxide phases formed on the $\mathrm{O}_{2} / \mathrm{Ar}$ flow ratio: (a) $1.05 \%$, (b) $1.51 \%$, (c) $1.97 \%$, (d) $3.07 \%$, (e) $3.55 \%$. Deposition parameters: Temperature $\left({ }^{\circ} \mathrm{C}\right)=450$; Time $(\min )=.60 ; \operatorname{Power}(\mathrm{W})=100$; Work pressure $(\mathrm{mbar})=8.4 \times 10^{-3}$.

Fig. 3 shows the dependence on the DC current applied. Also, in this case was possible to tune the oxide phase valence by changing the current. It was observed that an increase in the current, which leads to a higher sputtering yield, conducted to a higher vanadium content at a constant oxygen flow, and therefore, led to a higher vanadium content oxide. Although $\mathrm{VO}_{2}(\mathrm{M})$ and $\mathrm{VO}_{2}(\mathrm{~B})$ have the same theoretical stoichiometry, $\mathrm{VO}_{2}(\mathrm{M})$ seemed to require higher vanadium contents to form. 


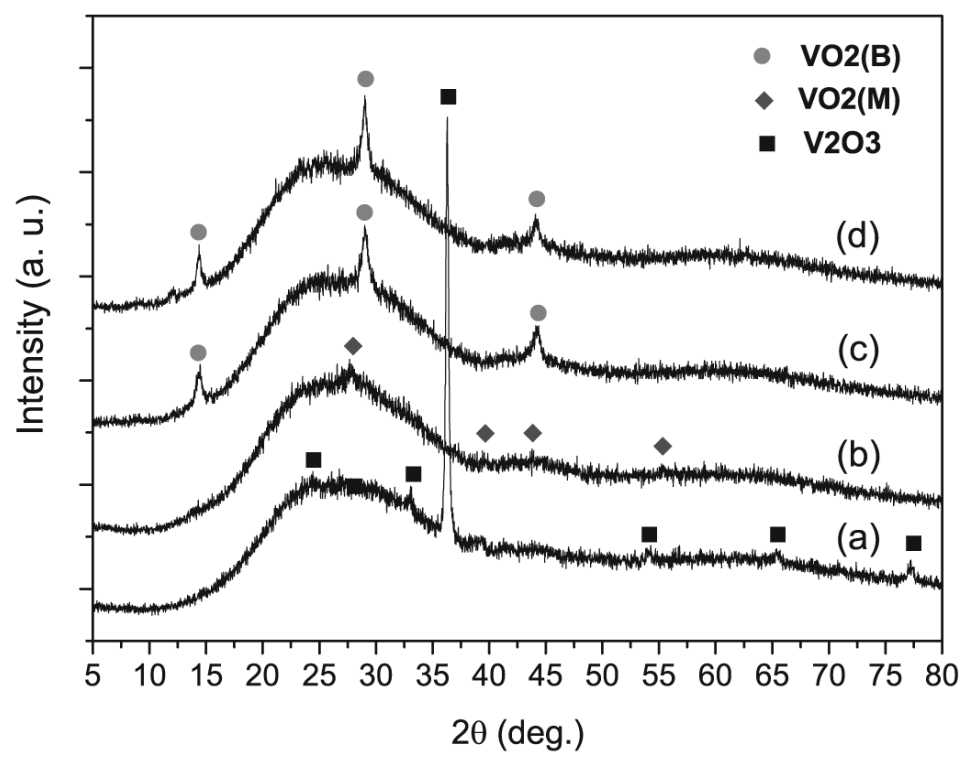

Fig. 3. XRD spectra showing the dependence of the vanadium oxide phases formed on the DC current: (a) $0.32 \mathrm{~A}$, (b) $0.31 \mathrm{~A}$, (c) $0.30 \mathrm{~A}$, (d) $0.28 \mathrm{~A}$. Deposition parameters: Temperature $\left({ }^{\circ} \mathrm{C}\right)=450$; Time $(\min )=.20 ; \mathrm{O}_{2} / \operatorname{Ar}$ flow $(\%)=2.61 ;$ Work pressure $(\operatorname{mbar})=8.4 \times 10^{-3}$.

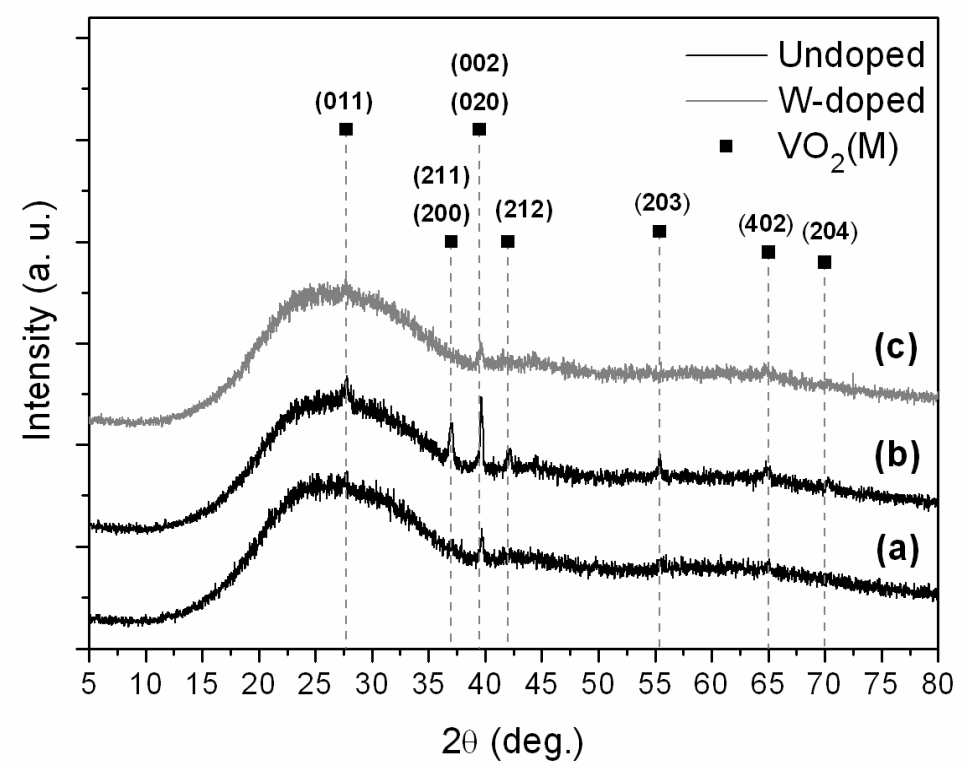

Fig. 4. XRD patterns of $\mathrm{VO}_{2}(\mathrm{M})$ thin films deposited under high growth rate conditions: (a) $t(\mathrm{~min})$ $=5 ;(\mathrm{b}) \mathrm{t}(\mathrm{min})=10 ;(\mathrm{c}) \mathrm{t}(\mathrm{min})=5$. Deposition parameters: Temperature $\left({ }^{\circ} \mathrm{C}\right)=450 ; \mathrm{I}(\mathrm{A})=0.5 ; \mathrm{O}_{2} / \mathrm{Ar}$ flow $(\%)=14.6$; Work pressure $($ mbar $)=4 \times 10^{-3}$.

In Fig. 4 are shown XRD patterns of undoped and $\mathrm{W}$-doped $\mathrm{VO}_{2}(\mathrm{M})$ thin films deposited under high growth rate conditions, for two different deposition times. Unlike the results shown by the undoped $\mathrm{VO}_{2}(\mathrm{M})$ films deposited under lower growth rate conditions (Fig. $2 \mathrm{~b}$ and Fig. 3b), these patterns reveal a preferable crystal orientation in the (002) plane rather than (011). The higher ion bombardment (higher ion kinetic energy), during film formation, as a consequence of increased target current and at the same time working at a lower pressure resulted in a higher deposition rate (about fivefold, as described in the next section) and preferred crystal orientation in the film plane, (002). In Fig. 4a, which represents the pattern of the film deposited for 5 minutes, is seen only the reflection of the (002) plane, no other peak is noticeable. The increase in the deposition duration to 
10 minutes led to a film with increased thickness and increased crystallinity, as observed in Fig. $4 \mathrm{~b}$ from the change in peak intensities. Other crystal orientations are noticeable, (011) and (200) although (002) is maintained as main preferred direction. The pattern (c) which represents the Wdoped film reveals a pattern similar to that of the undoped film deposited for the same time.

Surface morphology. Table 1 presents the deposition parameters and resulting phase composition of the samples used for the analyses presented in the subsequent sections.

Table 1. Processing conditions and resulting phases of the samples chosen for further analyses.

\begin{tabular}{lllllll}
\hline Sample & $\# 1^{\mathrm{a}}$ & $\# 2^{\mathrm{b}}$ & $\# 3^{\mathrm{c}}$ & $\# 4^{\mathrm{d}}$ & $\# 5^{\mathrm{e}}$ & $\# 6^{\mathrm{f}}$ \\
Phase & $\mathrm{VO}_{2}(\mathrm{M})$ & $\mathrm{VO}_{2}(\mathrm{M})$ & $\mathrm{VO}_{2}(\mathrm{M})$ & $\mathrm{VO}_{2}(\mathrm{~B})$ & $\mathrm{V}_{2} \mathrm{O}_{5}$ & $\mathrm{VO}_{2}(\mathrm{~b})+\mathrm{V}_{2} \mathrm{O}_{5}$ \\
Subs. temp. $\left[{ }^{\circ} \mathrm{C}\right]$ & 450 & 450 & 450 & 450 & 400 & 450 \\
Time [min.] & 60 & 20 & 5 & 20 & 20 & 60 \\
Pressure [mbar] & $8.4 \times 10^{-3}$ & $8.4 \times 10^{-3}$ & $4.0 \times 10^{-3}$ & $3.9 \times 10^{-3}$ & $6.4 \times 10^{-5}$ & $8.4 \times 10^{-3}$ \\
DC Power or Current [W or A] & $100 \mathrm{~W}$ & $0.31 \mathrm{~A}$ & $0.50 \mathrm{~A}$ & $0.25 \mathrm{~A}$ & $0.20 \mathrm{~A}$ & $100 \mathrm{~W}$ \\
$\mathrm{O}_{2}$ /Ar ratio [\%] & 1.51 & 2.61 & 14.60 & 6.25 & 50.00 & 1.97 \\
\hline
\end{tabular}

${ }^{a}$ pattern (b) in Fig. $2 ;^{b}$ pattern (b) in Fig. $3{ }^{c}$ identical to pattern (a) in Fig. 4; ${ }^{d}$ identical to pattern (d) in Fig. 3 ; ${ }^{\mathrm{e}}$ pattern (d) in Fig. $1 ;{ }^{\mathrm{f}}$ pattern (c) in Fig. 2.

In Fig. are depicted both SEM micrographs and AFM topographic maps showing the surface morphology of some of the vanadium oxide films prepared. As it can be noticed, both results are in perfect agreement. The morphological differences within the various films are obvious. Samples \#1 and $\# 2$, comprising the same phase, $\mathrm{VO}_{2}(\mathrm{M})$, reveal the same appearance of spherical-like grains with but with noticeable different mean sizes. The first one presents larger grains due to a longer deposition time (60 minutes against 20) which allowed a further growth and coalescence of grains. Unlike, sample \#3 which is also $\mathrm{VO}_{2}(\mathrm{M})$ presents a distinct appearance characterized by a dense and flat structure composed of long grains. Sample \#4 $\left(\mathrm{VO}_{2}(\mathrm{~B})\right)$ is very flat and with no particular features to be referred but some regions where the film is buckled due to low adherence and residual stresses [23]. Sample \#5 $\left(\mathrm{V}_{2} \mathrm{O}_{5}\right)$ reveals elongated grains, oriented mainly in the film plane, embedded in a very compact matrix. Sample \#6, being a mixture of $\mathrm{V}_{2} \mathrm{O}_{5}$ and $\mathrm{VO}_{2}(\mathrm{~B})$ has a different morphology of both separate as seen in Fig.(d) and (e). The film reveals a high density of grains lying on the film plane and many agglomerates displayed perpendicularly to the film. It should be noted that this sample was gown for $60 \mathrm{~min}$. instead of 20 as for samples \#4 and \#5.

AFM is an useful tool as a complement to SEM allowing manipulation of the height maps to perform statistical analysis concerning to grain shape, size and orientation, roughness, textures, etc. The roughness parameters of each sample were determined and can be found in Table 2. $R_{\mathrm{a}}$ represents the average surface roughness or average deviation, $R_{\mathrm{q}}$ is the root-mean-square (rms) average or standard deviation and $R_{\max }$ is the difference between the highest peak and the deepest valley. The roughness parameters presented in Table 2 are intended to complement the maps bringing further information on the levels of flatness of the films. Grain sizes have also been determined for sample \#1, \#2 and \#5. Samples \#1 and \#2 presented grain size averages of 65 and $45 \mathrm{~nm}$, respectively. Sample \#5 revealed elongated grains with average length and width of 91 and $33 \mathrm{~nm}$, respectively. 



(a)

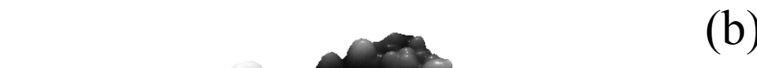

(b)

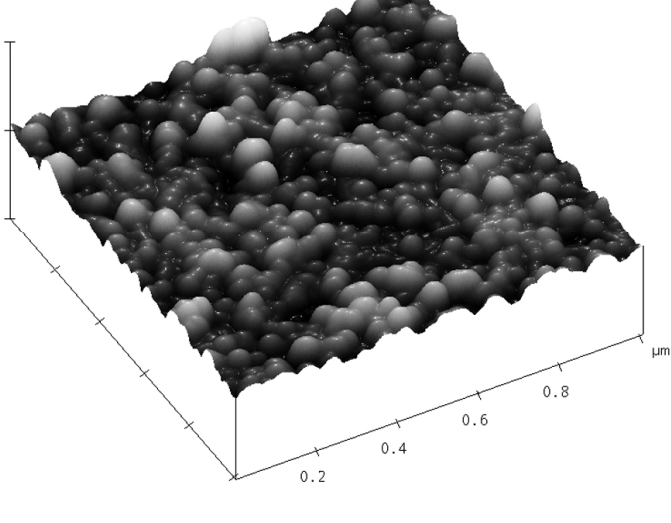

(c)



Fig. 5. Secondary electron micrographs of the surface of the VOx thin films (on the left) and respective AFM topographic maps (right side): (a) sample \#1 - $\mathrm{VO}_{2}(\mathrm{M})$; (b) sample $\# 2$ - $\mathrm{VO}_{2}(\mathrm{M})$; (c) sample \#3 - $\mathrm{VO}_{2}(\mathrm{M})$; (d) sample \#4 - $\mathrm{VO}_{2}(\mathrm{~B})$; (e) sample \#5 - $\mathrm{V}_{2} \mathrm{O}_{5}$; (f) sample \#6 $\mathrm{V}_{2} \mathrm{O}_{5}+\mathrm{VO}_{2}(\mathrm{~B})$. 

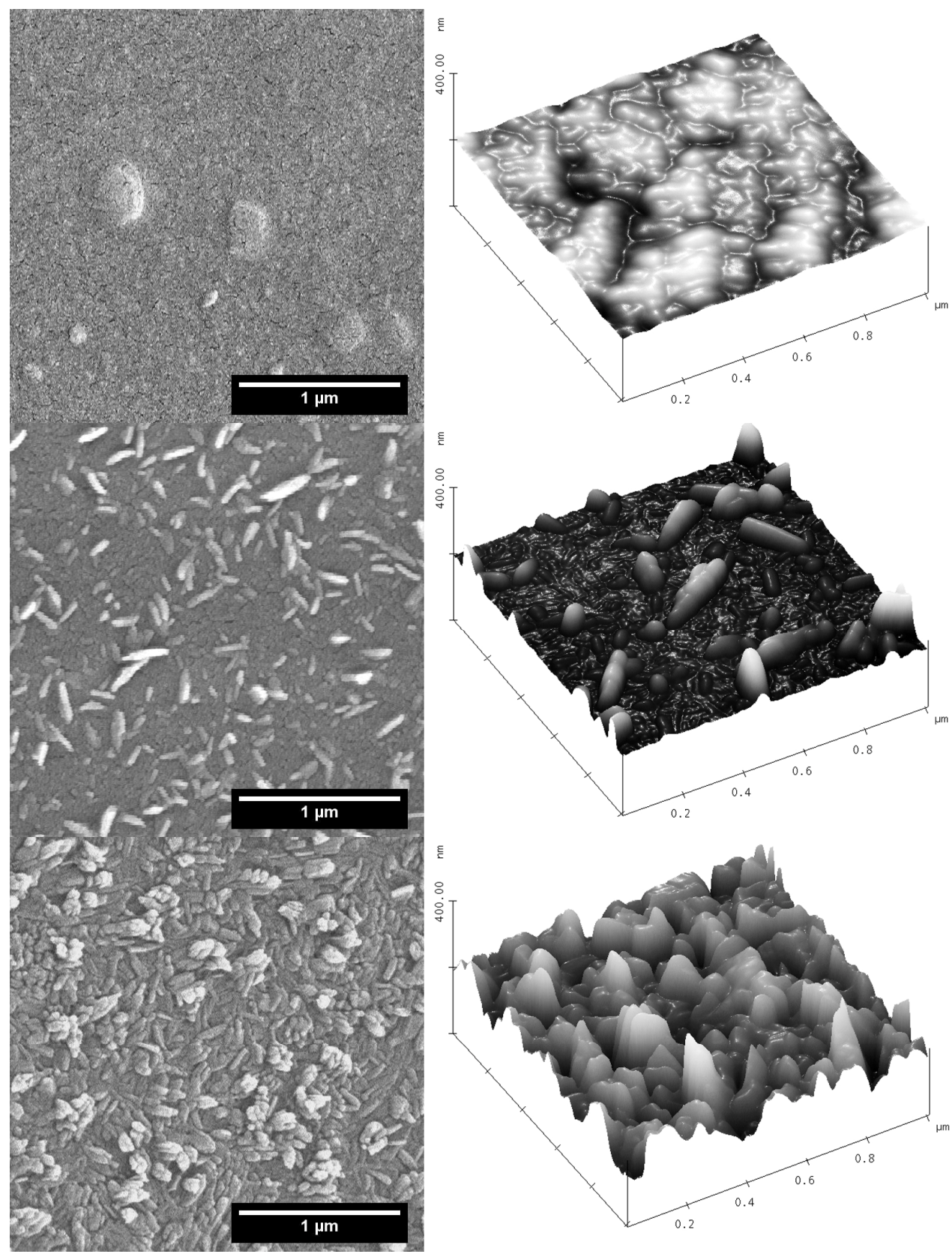

(d)

(e)

(f)

Fig. 5. Cont.

Table 2. Roughness parameters of the VOx films determined by AFM.

\begin{tabular}{ccccccc}
\hline Sample & $\# 1$ & $\# 2$ & $\# 3$ & $\# 4$ & $\# 5$ & $\# 6$ \\
Ra $(\mathrm{nm})$ & 10.64 & 9.94 & 4.44 & 3.53 & 10.90 & 30.57 \\
Rq $(\mathrm{nm})$ & 13.83 & 12.64 & 5.49 & 4.35 & 15.81 & 38.95 \\
Rmax (nm) & 109.72 & 96.73 & 37.82 & 27.35 & 115.42 & 276.14 \\
Grain size (nm) & 65 & 45 & - & - & $91 \times 33$ & - \\
\hline
\end{tabular}

Fig. 6 shows cross-sections of $\mathrm{VO}_{2}(\mathrm{M})$ films, deposited in the same conditions as sample \#3, which allowed determining film thicknesses and estimate the growing rates. The films measured, in average, 170 and $370 \mathrm{~nm}$ for 7 and 15 minutes respectively. The resulting growing rate is linear and about $25 \mathrm{~nm} / \mathrm{min}$, which is fivefold of that obtained for samples $\# 1$ and $\# 2(\sim 5 \mathrm{~nm} / \mathrm{min})$. 

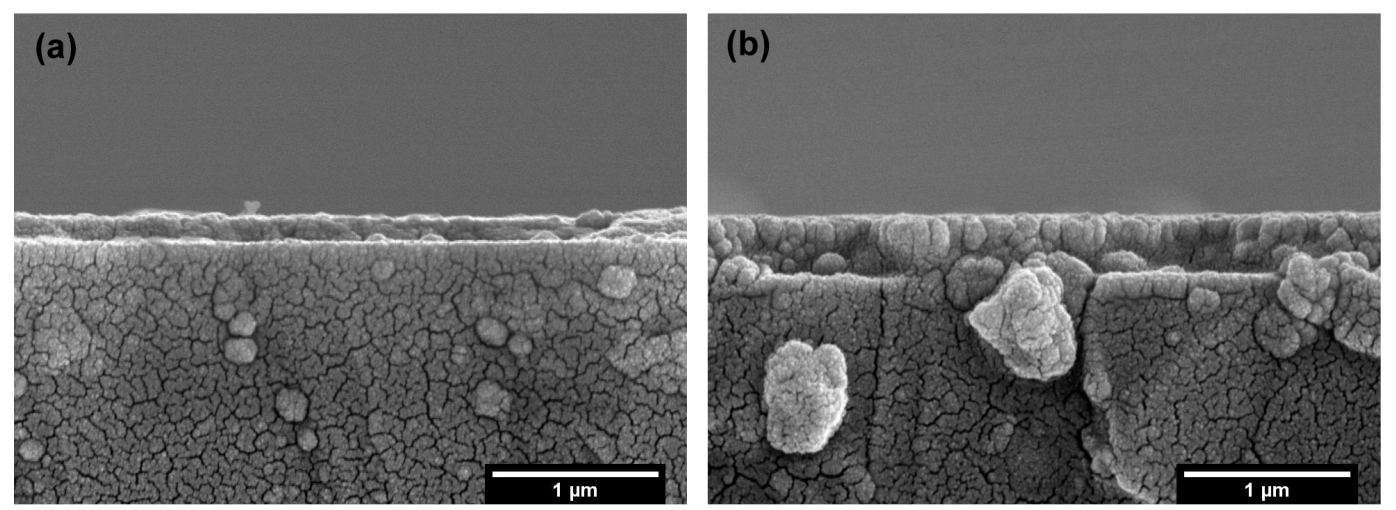

Fig. 6. Cross-sectional view of $\mathrm{VO}_{2}(\mathrm{M})$ films deposited in the same conditions as sample \#3 but for 7 min. (a) and 15 min. (b).

\section{Thermochromism of $\mathrm{VO}_{2}(\mathrm{M})$ films.}

Fig. 7 compares the optical transmittance spectra of the $\mathrm{VO}_{2}(\mathrm{M})$ samples $\# 1$ and $\# 2$ at 20 and $70^{\circ} \mathrm{C}$, on the semiconducting and metallic states, respectively. Sample \#1 with a thickness of about $300 \mathrm{~nm}$, measured by SEM, shows a lower optical transmittance within the visible region $(\sim 10 \%)$ when compared with sample \#2 $(\sim 30 \%)$ which is about $100 \mathrm{~nm}$ thick. However, at the infrared region, the thicker film exhibits an increased thermochromic effect. For instance, at a wavelength of about $2000 \mathrm{~nm}$, sample \#1 shows a drop in the transmittance from nearly $50 \%$ to nearly $0 \%$ while sample \#2 shows a drop from about 30\% to $10 \%$. This difference is not only related to the thickness itself but also to the crystallinity of the film. It has been shown by SEM and AFM that grain shapes are identical for both samples but the sizes are distinct, being the sample with the larger grain average size the one which noticeably shows a more abrupt switch in the optical transmittance at the near infrared range. The sharpness of transition could also be attributed to a closer stoichiometry of that of exact $\mathrm{VO}_{2}$ [22]. There exists a compromise between transparency and thermochromism. An improved thermochromism, characterized by a wide switch at the infrared, requires films with relatively high thicknesses and therefore low transparency on the visible region is an unfortunate consequence.


Fig. 7. Optical transmittance spectra of the $\mathrm{VO}_{2}(\mathrm{M})$ samples on semiconducting $\left(20^{\circ} \mathrm{C}\right)$ and metallic states $\left(70^{\circ} \mathrm{C}\right)$; (a) sample \#01; (b) sample \#2. 

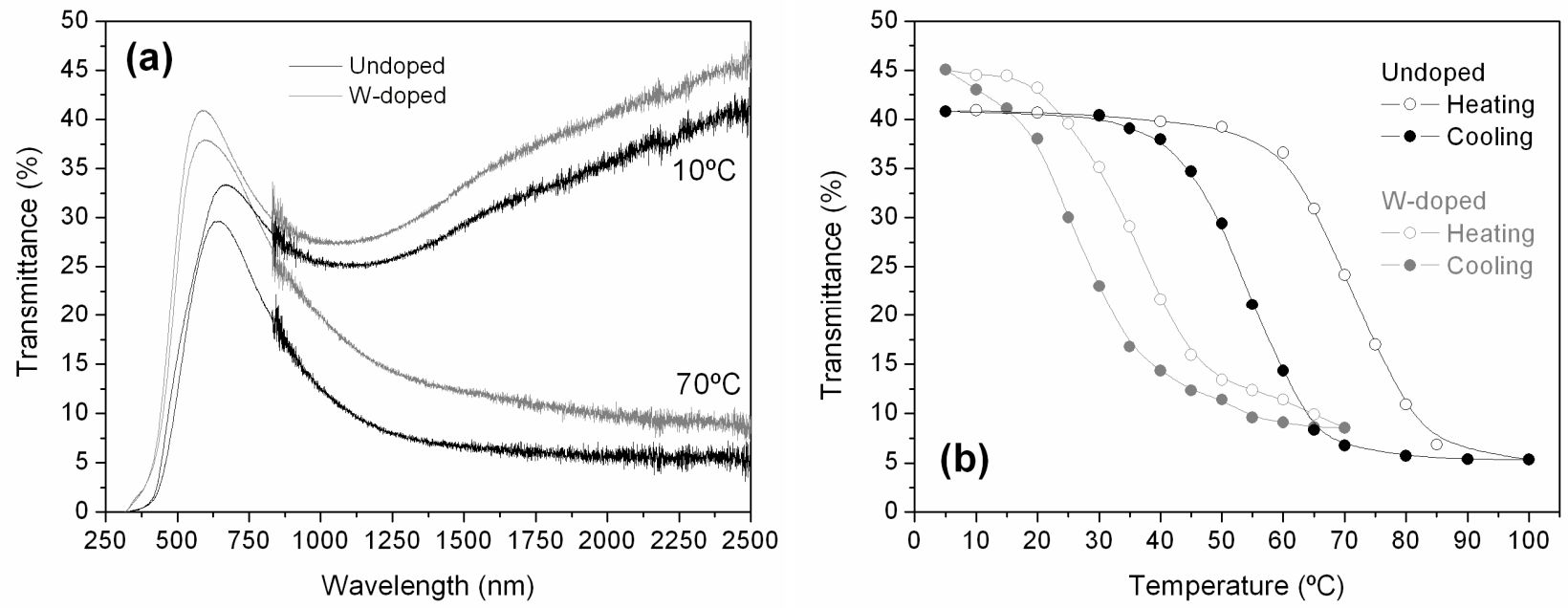

Fig. 8. Optical transmittance spectra (a) in the UV-VIS-NIR range and hysteresis loop (b) taken at $\lambda=2500 \mathrm{~nm}$ of undoped (sample \#3) and $\mathrm{W}$-doped $\mathrm{VO}_{2}(\mathrm{M})$ films.

In Fig. 8 is illustrated the optical transmittance spectra of $\mathrm{VO}_{2}(\mathrm{M})$ films deposited under high growth conditions, both undoped and W-doped. It can be observed in Fig. 8a that both the $\mathrm{VO}_{2}$ films present a significant thermochromic behavior by exhibiting a large switch in the optical transmittance at the near infrared wavelength range. The films present reasonably good transparencies showing maximum transmittances at the visible range around 35 and $40 \%$ for the undoped and W-doped, respectively. Moreover, the $\mathrm{W}$-doped film presents the maximum at the visible range shifted to a lower wavelength value resulting in a green color instead of brown-yellow. Fig. $8 \mathrm{~b}$ shows the optical transmittance hysteresis loops during heating and cooling for the same films. The W-doped film reveals an obvious decrease of the transition temperature and a narrow temperature hysteresis and maintains the good thermochromic switch. The transition temperatures were estimated to be 31 and $63^{\circ} \mathrm{C}$ for the $\mathrm{W}$-doped and undoped $\mathrm{VO}_{2}$ films, respectively, by differentiating both curves and averaging the center of the two Gaussian fittings. Comparing Fig. 8a with Fig. $7 \mathrm{~b}$ it can be seen there is an improvement in both transparency at the visible and thermochromic behavior. It should be referred that sample \#3 has a thickness of about $125 \mathrm{~nm}$ while sample \#2 is $100 \mathrm{~nm}$ thick. The orientation of the film in the (002) direction, parallel to the substrate plane, resulted in a higher transparency at the visible and an improved thermochromic behavior.

\section{Conclusions}

Nanocrystalline vanadium oxide thin films have been successfully deposited by reactive DC magnetron sputtering under different processing conditions. The effect of $\mathrm{O}_{2} / \mathrm{Ar}$ flow ratio and DC current on vanadium oxide phase formation has been studied. Single and multiple phase vanadium oxides have been found. With the change of the oxygen/argon flow ratio, at the appropriate temperature and total pressure, vanadium oxide films with different oxygen valences can be obtained. At a given $\mathrm{O}_{2} /$ Ar flow ratio it is also possible to tune the desirable phase by changing the $\mathrm{DC}$ current. With respect to the thermochromic $\mathrm{VO}_{2}(\mathrm{M})$ films, the increase in thickness, and grain size, enhances the thermochromic switch in the infrared range, however it decreases the transmittance in the visible range. Moreover, $\mathrm{VO}_{2}(\mathrm{M})$ films prepared under high growth rate conditions revealed main crystal orientation in the (002) plane and exhibited higher transparency in the visible region and improved thermochromic behavior compared to those oriented mainly in the (011) direction. 


\section{Acknowledgements}

This work is part of the research project "Termoglaze - Production of thermochromic glazings for energy saving applications" - FP6-017761, funded by the European Commission. C. Batista acknowledges the PhD grant from FCT-Fundação para a Ciência e a Tecnologia.

\section{References}

[1] A. Zylbersztejn and N.F. Mott, Physical Review B 11 (1975) 4383 LP - 4395.

[2] B.G. Chae, H.T. Kim, D.H. Youn and K.Y. Kang, Physica B-Condensed Matter 369 (2005) 76-80.

[3] H.C. Wang, X.J. Yi and Y. Li, Optics Communications 256 (2005) 305-309.

[4] S. Chen, X. Yi, H. Ma, H. Wang, X. Tao, M. Chen and C. Ke, Optical and Quantum Electronics 35 (2003) 1351-1355.

[5] M. Seman, J. Marino, W.L. Yang and C.A. Wolden, Journal of Non-Crystalline Solids 351 (2005) 1987-1994.

[6] A.W. Smith, Applied Physics Letters 23 (1973) 437.

[7] I. Balberg and S. Trokman, Journal of Applied Physics 46 (1975) 2111.

[8] I.P. Parkin and T.D. Manning, Journal of Chemical Education 83 (2006) 393-400.

[9] T.D. Manning, I.P. Parkin, M.E. Pemble, D. Sheel and D. Vernardou, Chemistry of Materials 16 (2004) 744-749.

[10] Li-Jian Meng, Rui A. Silva, Hain-Ning Cui, Vasco Teixeira, M.P. dos Santos, Zheng Xu, Thin Solid Films, 515 (2006) 195-200

[11] G. Xu, P. Jin, M. Tazawa and K. Yoshimura, Solar Energy Materials and Solar Cells 83 (2004) 29-37.

[12] Hai-Ning Cui, Vasco Teixeira, Li-Jian Meng, Rong Wang, Jin-Yue Gao, Elvira Fortunato, Thin Solid Films, 516 (2008) 1484-1488

[13] K.D. Rogers, J.A. Coath and M.C. Lovell, Journal of Applied Physics 70 (1991) 1412-1415.

[14] A. Leone, A.M. Trione and F. Junga, Ieee Transactions on Nuclear Science 37 (1990) 17391743.

[15] F. Guinneton, J.-C. Valmalette and J.-R. Gavarri, Optical Materials 15 (2000) 111-114.

[16] C.H. Griffith and H.K. Eastwood, Journal of Applied Physics 45 (1974) 2201-2206.

[17] J.F. Smith. ASM international, Metals Park, Ohio 1989.

[18] M.G. Krishna, Y. Debauge and A.K. Bhattacharya, Thin Solid Films 312 (1998) 116-122.

[19] N. Renard, C. Sella, O. Nemraoui, M. Maaza, Y. Sampeur and J. Lafait, Surface and Coatings Technology 98 (1998) 1477-1482.

[20] M.A. Sobhan, R.T. Kivaisi, B. Stjerna and C.G. Granqvist, Solar Energy Materials and Solar Cells 44 (1996) 451-455.

[21] Vasco Teixeira (invited lecture), "Advanced and Novel Coatings Systems for the Vacuum Coatings and Metallizing Industry", Vacuum \& Metallizing Industry Conference 2006, organized by AWA-Alexander Watson Associates, 4-5 December 2006, Amsterdam, the Netherlands

[22] K.D. Rogers, J.A. Coath and M.C. Lovell, Journal of Applied Physics 70 (1991) 1412-1415.

[23] V. Teixeira, Thin Solid Films 392 (2001) 276-281 